\title{
Impact of exenatide on mitochondrial lipid metabolism in mice with nonalcoholic steatohepatitis
}

\author{
Srilaxmi Kalavalapalli, Fernando Bril1, Joy Guingab², Ariana Vergara¹, Timothy J Garrett², Nishanth E Sunny³ and \\ Kenneth Cusi1,4
}

1Division of Endocrinology, Diabetes and Metabolism, Department of Medicine, University of Florida, Gainesville, Florida, USA 2Department of Pathology, University of Florida, Gainesville, Florida, USA

${ }^{3}$ Department of Animal and Avian Sciences, University of Maryland, College Park, Maryland, USA

${ }^{4}$ Division of Endocrinology, Diabetes and Metabolism, Malcom Randall Veterans Administration Medical Center (VAMC), Gainesville, Florida, USA

Correspondence should be addressed to K Cusi: Kenneth.Cusi@medicine.ufl.edu

\begin{abstract}
Exenatide (Exe) is a glucagon-like peptide (GLP)-1 receptor agonist that enhances insulin secretion and is associated with induction of satiety with weight loss. As mitochondrial dysfunction and lipotoxicity are central features of nonalcoholic steatohepatitis (NASH), we tested whether Exe improved mitochondrial function in this setting. We studied C57BL/6] mice fed for 24 weeks either a control- or high-fructose, high-transfat (TFD)-diet (i.e., a NASH model previously validated by our laboratory). For the final 8 weeks, mice were treated with Exe $(30 \mu \mathrm{g} / \mathrm{kg} /$ day $)$ or vehicle. Mitochondrial metabolism was assessed by infusion of $\left[{ }^{13} C_{3}\right]$ propionate, $\left[3,4-{ }^{13} C_{2}\right]$ glucose and NMRbased ${ }^{13} \mathrm{C}$-isotopomer analysis. Exenatide significantly decreased fasting plasma glucose, free fatty acids and triglycerides, as well as adipose tissue insulin resistance. Moreover, Exe reduced 23\% hepatic glucose production, 15\% tri-carboxylic acid (TCA) cycle flux, $20 \%$ anaplerosis and $17 \%$ pyruvate cycling resulting in a significant $31 \%$ decrease in intrahepatic triglyceride content $(P=0.02)$. Exenatide improved the lipidomic profile and decreased hepatic lipid byproducts associated with insulin resistance and lipotoxicity, such as diacylglycerols (TFD: $111 \pm 13$ vs Exe: $64 \pm 13 \mu \mathrm{mol} / \mathrm{g}$ protein, $P=0.03$ ) and ceramides (TFD: $1.6 \pm 0.1$ vs Exe: $1.3 \pm 0.1 \mu \mathrm{mol} / \mathrm{g}$ protein, $P=0.03$ ). Exenatide lowered expression of hepatic lipogenic genes (Srebp1C, Cd36) and genes involved in inflammation and fibrosis (Tnfa, Timp1). In conclusion, in a diet-induced mouse model of $\mathrm{NASH}$, Exe ameliorates mitochondrial TCA cycle flux and significantly decreases insulin resistance, steatosis and hepatocyte lipotoxicity. This may have significant clinical implications to the potential mechanism of action of GLP-1 receptor agonists in patients with NASH. Future studies should elucidate the relative contribution of direct vs indirect mechanisms at play.
\end{abstract}
Key Words
- nonalcoholic fatty liver disease
- liver metabolism
- insulin resistance
- lipidomics

(c) 2019 Society for Endocrinology Published by Bioscientifica Ltd. Printed in Great Britain
Journal of Endocrinology (2019) 241, 293-305 


\section{Introduction}

Nonalcoholic fatty liver disease (NAFLD) is characterized by intrahepatic triglyceride accumulation, hepatic insulin resistance and dysregulated mitochondrial metabolism. About $70 \%$ of patients with obesity or type 2 diabetes mellitus (T2DM) have NAFLD (Rinella 2015, Bril \& Cusi 2016, Cusi 2016), and as many as $\sim 30-50 \%$ may develop the more severe form of the disease known as nonalcoholic steatohepatitis (NASH), characterized by hepatocyte necrosis (ballooning) and lobular inflammation, and often with progressive fibrosis (Cusi 2012). In the setting of obesity or diabetes, NASH is frequently associated with fibrosis and a more rapid progression of fibrosis. Therefore, patients that develop NASH have a high risk for cirrhosis as well as cardiovascular disease from a more unfavorable cardiovascular risk profile (Charlton et al. 2011).

Abnormal mitochondrial oxidative metabolism is a central feature for the transition from isolated steatosis to NASH (Sunny et al. 2010, Satapati et al. 2012). Hepatic insulin resistance and inflammation, two key components of NASH, are closely associated with alterations in mitochondrial oxidative metabolism ( $\beta$-oxidation, TCA cycle and mitochondrial respiration) in several rodent models of NAFLD (Satapati et al. 2012, 2015, Patterson et al. 2016, Kalavalapalli et al. 2018). In humans, several studies have reported abnormal mitochondrial fatty acid oxidation and ATP generation in NAFLD using different techniques (Sunny et al. 2017) and even with complex measurements of TCA cycle activity (Sunny et al. 2011) and in direct tissue assessments of mitochondrial function (Koliaki et al. 2015). However, the underlying mechanisms by which these alterations in mitochondrial metabolism mediate the progression of the disease are not well understood. It appears that chronic induction of mitochondrial oxidative flux can drive reactive oxygen species (ROS) generation and inflammation in NASH (Satapati et al. 2015). As shown earlier by our laboratory, despite elevated TCA cycle activity, lipotoxic intermediates from incomplete fat oxidation (ceramides and diacylglycerols) can accumulate in mice models of NASH (Patterson et al. 2016).

Among the many approaches under investigation for NASH, glucagon-like peptide-1 receptor agonists (GLP-1RAs) have shown a significant promise for the treatment of NAFLD (Ding et al. 2006, Blonde \& RussellJones 2009, Cusi 2012, Armstrong et al. 2013, 2016a,b, Van Can et al. 2014, Xu et al. 2014, Abdul-Ghani et al. 2017). Exenatide, a glucagon-like peptide-1 receptor agonist, binds to and activates the GLP-1 receptor to enhance glucose-dependent insulin secretion, glucosedependent suppression of inappropriately high glucagon secretion, slow of gastric emptying and induce satiety with induction of weight loss (Amori et al. 2007, Xu et al. 2014, Dutour et al. 2016, Dhir \& Cusi 2018). They have shown beneficial effects in rodent models of NASH (Trevaskis et al. 2012, Xu et al. 2014). In a meta-analysis of 6 RCT LEAD (Liraglutide Efficacy and Action in Diabetes) trials, a significant decrease in plasma aminotransferase and hepatic steatosis (assessed by CT scan) was observed at the higher dose of liraglutide $(1.8 \mathrm{mg})$, an effect closely related to the magnitude of weight loss (Armstrong et al. 2013). Several small uncontrolled studies have reported benefit with GLP-1RAs in NAFLD (Jendle et al. 2009, Eguchi et al. 2015, Dong et al. 2017). Significant liver histological benefit was observed in patients with biopsy-proven NASH treated with liraglutide for 48 weeks (Armstrong et al. 2016a). However, the exact mechanisms of GLP-1RAs on liver mitochondrial function and hepatic steatosis remain incompletely understood.

The objective of this study was to examine if exenatide treatment could improve hepatic glucose and mitochondrial metabolism in a high-fructose, high trans-fat diet mice model of NASH. We hypothesized that exenatide treatment in mice with NASH will alleviate distinctive hepatocyte mitochondrial defects, such as increased TCA cycle flux and the accumulation of lipotoxic intermediates.

\section{Materials and methods}

\section{Materials and reagents}

$\left[3,4-{ }^{13} \mathrm{C}_{2}\right]$ glucose $(98 \%)$ was purchased from Omicron Biochemicals (South Bend, IN, USA). [U-13C]propionate was purchased from Cambridge Isotopes (Andover, MA, USA). Internal standards, including ceramide (d18:1/17:0) and d5-DG Internal standard mixture I were purchased from Avanti Lipids (Alabaster, AL, USA). Other common chemicals were obtained from Sigma.

\section{Animals and diets}

Mouse studies were approved by the Institutional Animal Care and Use Committee at University of Florida. Male C57BL/6 mice were obtained from Jackson Laboratories at $\sim 7$ weeks of age and the diets were purchased from Research Diets. Mice were randomly assigned to a control group (C; 10\% Kcal fat; Research Diets, Inc. \#D09100304; $n=8$ ) or a high-fructose high trans-fat diet 
(TFD; 40\% Kcal fat, 20\% Kcal fructose, 2\% cholesterol; Research Diets, Inc.\# D09100301; $n=20)$. Mice were kept on the above diets for a period of 24 weeks, the period of time needed for the TFD diet-fed mice to develop NASH, as validated earlier by Clapper et al. (Trevaskis et al. 2012, Clapper et al. 2013) and in prior by our laboratory (Patterson et al. 2016, Kalavalapalli et al. 2018). Eight weeks prior to the metabolic studies with stable isotope infusions, miniosmotic pumps (ALZET osmotic pumps, Cupertino, CA, USA) were implanted subcutaneously into all animals (C and TFD groups). Control mice received 10\% DMSO in saline as vehicle and TFD-fed mice were randomly assigned to either vehicle or exenatide (Exe; $30 \mu \mathrm{g} / \mathrm{kg}$ per day in 10\% DMSO) (Mack et al. 2006) by continuous infusion for the next 8 weeks. The mini-osmotic pump was replaced at 4 weeks (maximal duration of use) and a second one implanted for the last 4 weeks of the study. After a total of 8 weeks of drug delivery starting at 16 weeks on either diet, stable isotope infusions and metabolic analysis were performed at 24 weeks.

\section{In vivo stable isotope infusion}

Five days prior to the hepatic flux analysis, a jugular vein catheter was implanted into the mice for the infusion of stable isotopes. Following an overnight fast (12h; consistent with our prior studies), mice were infused a mixture containing $\left[{ }^{13} \mathrm{C}_{3}\right]$ propionate to determine mitochondrial fluxes and $\left[3,4-{ }^{13} \mathrm{C}_{2}\right]$ glucose to determine endogenous glucose production (EGP) for $90 \mathrm{~min}$. Upon completion of the infusion, blood was collected by exsanguination under anesthesia and processed for ${ }^{13} \mathrm{C}$-nuclear magnetic resonance (NMR)- based isotopomer analysis (Satapati et al. 2012). Tissues were flash frozen in liquid nitrogen and stored at $-80^{\circ} \mathrm{C}$ until further analysis.

\section{Analysis of mitochondrial TCA cycle metabolism and EGP by NMR}

Blood glucose was converted to the 1,2-isopropylidene glucofuranose derivative (mono acetone glucose, MAG). MAG was analyzed by ${ }^{13} \mathrm{C}$ isotopomer analysis on a 600 $\mathrm{MHz}$, Agilent NMR spectrometer. Peak areas were analyzed using 1D NMR software ACD/Labs 9.0 before metabolic analysis as reported previously (Satapati et al. 2012). The isotopomer analysis of the multiplets arising from ${ }^{13} \mathrm{C}$ labeling of carbon-2 of glucose was used to determine direct functional activity of hepatic TCA cycle metabolism, including gluconeogenesis, mitochondrial anaplerosis and TCA cycle flux. These relative mitochondrial fluxes were converted to absolute fluxes by normalizing with EGP (Satapati et al. 2012, Patterson et al. 2016).

\section{Analysis of lipids by liquid chromatography and tandem mass spectrometry (LC-MS/MS)}

Approximately 20-25 mg fine powdered mice liver tissue was used for lipidomic analysis by LC-MS/MS. Relative concentrations of various lipid classes including triacylglycerols (TGs), diacylglycerol (DAGs), ceramides (Cer), lysophosphatidylcholine (LPC), phosphatidylcholine (PC), phosphatidylethanolamine (PE) and phosphatidylglycerol (PG) were determined as described previously (Koelmel et al. 2017). In brief, liver tissue was homogenized with ceramic beads along with the internal standards, Cer (d18:1/17:0) and d5-DG internal standard mixture I, in chloroform: methanol $(2: 1, \mathrm{v} / \mathrm{v})$. Lipids were extracted by folch extraction (Folch et al. 1957) for the determination of metabolite concentrations. Metabolites were quantified by peak area comparison to their respective or a representative internal standard. Hepatic lipids were identified with heated electrospray ionization probe (HESI II) and a Q-Exactive Orbitrap (Thermo Scientific) was used to acquire mass spectra in full scan mode using data-dependent top5 analysis (ddMS2 -top5) in both positive and negative polarity. Feature processing was done by MZmine 2.0 and lipids were identified using LipidMatch (Pluskal et al. 2010, Koelmel et al. 2017). Only exact mass of the MS/MS fragments was used for matching. After identification, lipids were quantified using LipidMatch Quant, which uses the closest eluting standard representative of a lipids class for relative quantification of each respective feature. Both LipidMatch and LipidMatch Quant are available at http://secim.ufl.edu/secim-tools/.

\section{Gene expression analysis}

As previously reported (Patterson et al. 2016), frozen liver was ground to fine powder in liquid nitrogen. Total mRNA was extracted from liver tissue by TRIzol method and converted to cDNA using cDNA Reverse Transcription kit (Bio-Rad, iScript cDNA synthesis kit). $25 \mathrm{ng}$ cDNA was amplified by quantitative real-time PCR (CFX Real-Time system, Bio-Rad, C1000 Touch Thermal Cycler) using SYBR GreenER qPCR SuperMix. Primers were purchased from IDT (Integrated DNA Technologies, Iowa). The comparative threshold method was used to determine the relative mRNA levels. Gene expression was normalized to cyclophilin b (Ppib) which was used as the internal control. Primer sequences available upon request. 


\section{Biochemical measurements}

Fasting plasma total ketone and free fatty acid (FFA) concentrations were determined using an analytical kit (Wako Chemicals, Richmond, VA, USA). Fasting plasma insulin was measured by enzyme linked immunoassay using the mouse Insulin ELISA kit (Crystal Chem Inc., Downers Grove, IL, USA). Plasma and liver triglyceride concentrations were determined using an analytical kit (Sigma). Plasma cytokine concentrations of IL1b and TNFa were determined using mouse cytokine magnetic bead panel kit purchased from Milliplex/Millipore Corporation. All assays were performed according to the manufacturer's instructions.

\section{Statistics}

Data were expressed as means \pm s.e., and differences between groups were analyzed using one-way ANOVA and post hoc analysis adjusted for Bonferroni's multiple comparisons test. Comparisons between two groups were done using an unpaired Student's t-test and were considered significantly different at $P \leq 0.05$. Statistical analyses for the lipidomics data were performed in $\mathrm{R}$, version 3.1.2. In order to maximize the separation and understand which variables are responsible for the detected separation between the groups we conducted a multivariate analysis for all classes of lipids using Partial Least Squares Discriminant Analysis (PLS-DA) in MetaboAnalyst 3.0. A quality of prediction $\left(Q^{2}\right)$ value greater than 0.5 and an index of reproducibility of the
PLS-DA model $\left(R^{2}\right)$ value greater than 0.6 , were considered good for the PLS-DA analysis.

\section{Results}

Exenatide administration reduces body weight, fasting plasma glucose and FFAs in mice with NASH

The metabolic characteristics of mice (C and TFD after vehicle or Exe treatment) are presented in Table 1. As expected, 24 weeks of a TFD resulted in significant weight gain. Before the administration of specific diets, body weights were similar between groups (C: $19.6 \pm 0.8 \mathrm{~g}$, TFD: $19.6 \pm 0.7 \mathrm{~g}$, Exe: $19.2 \pm 0.7 \mathrm{~g}$ ). At 16 weeks before surgery and treatment, weights were equally increased in TFD and Exe mice compared to control animals (C: $28.3 \pm 0.7 \mathrm{~g}$, TFD: $37.3 \pm 1.1 \mathrm{~g}$, Exe: $39.2 \pm 1.3 \mathrm{~g}$ ). Administration of exenatide for 8 weeks reduced body weight and liver weight significantly. Exenatide lowered fasting plasma glucose levels in mice with NASH. Plasma triglycerides and nonesterified fatty acid levels were significantly lower in exenatide-treated mice. Taken together, these results suggest that exenatide treatment improved glucose metabolism and whole body insulin sensitivity.

\section{Effect of exenatide treatment on hepatic glucose production and TCA cycle activity in TFD mice}

We have previously reported that with the onset of NAFLD, both in rodent models (Patterson et al. 2016, Kalavalapalli et al. 2018) and in human subjects (Sunny et al. 2011),

Table 1 Metabolic characteristics of C57BI/6J mice fed either control (C), high-fructose-high trans-fat (TFD) or the TFD mice treated with Exenatide (Exe).

\begin{tabular}{l}
\hline \\
\hline Body weight, g \\
Fasting plasma glucose, $\mathrm{mg} / \mathrm{dL}$ \\
Fasting plasma insulin, $\mathrm{ng} / \mathrm{mL}$ \\
$\mathrm{HIRI}, \mathrm{ng} / \mathrm{mL} \times \mu \mathrm{mol} / \mathrm{min}$ \\
Fasting plasma FFA, $\mathrm{mM}$ \\
Adipo-IR ${ }_{\mathrm{i}}, \mathrm{mM} \times \mathrm{ng} / \mathrm{mL}$ \\
Fasting plasma ketones, $\mu \mathrm{M}$ \\
Fasting plasma triglyceride, $\mathrm{mg} / \mathrm{mL}$ \\
Plasma IL $1 \beta, \mathrm{pg} / \mathrm{mL}$ \\
Plasma TNF $\alpha, \mathrm{pg} / \mathrm{mL}$ \\
Liver weight, $\mathrm{g}$ \\
\% liver weight (per body) \\
Liver triglyceride, $\mathrm{mg} / \mathrm{g}$ liver \\
Liver protein, $\mathrm{mg} /$ whole liver
\end{tabular}

\begin{tabular}{c}
\hline $\mathbf{c}$ \\
\hline $26.5 \pm 1.5$ \\
$94.0 \pm 3.6$ \\
$0.06 \pm 0.01$ \\
$0.3 \pm 0.1$ \\
$0.19 \pm 0.02$ \\
$0.011 \pm 0.002$ \\
$678 \pm 147$ \\
$0.49 \pm 0.03$ \\
$4.6 \pm 2.2$ \\
$2.6 \pm 0.4$ \\
$1.6 \pm 0.1$ \\
$6.3 \pm 0.6$ \\
$145 \pm 25$ \\
$257 \pm 6$
\end{tabular}

\begin{tabular}{c}
\hline TFD \\
\hline $32.7 \pm 0.7^{*}$ \\
$100.1 \pm 5.5$ \\
$0.19 \pm 0.03^{*}$ \\
$1.2 \pm 0.2^{*}$ \\
$0.21 \pm 0.02$ \\
$0.041 \pm 0.005^{*}$ \\
$1363 \pm 68^{*}$ \\
$0.43 \pm 0.01$ \\
$31.4 \pm 4.9^{*}$ \\
$6.9 \pm 0.5^{*}$ \\
$4.5 \pm 0.4^{*}$ \\
$13.7 \pm 1.1^{*}$ \\
$287 \pm 23^{*}$ \\
$155 \pm 5^{*}$
\end{tabular}

\begin{tabular}{c}
\hline Exe \\
\hline $29.8 \pm 1.2^{\#}$ \\
$82.8 \pm 4.1^{\#}$ \\
$0.16 \pm 0.03^{\$}$ \\
$0.8 \pm 0.2^{\$}$ \\
$0.15 \pm 0.02^{\#}$ \\
$0.022 \pm 0.004^{\#}$ \\
$1492 \pm 159 \$$ \\
$0.37 \pm 0.02^{\#, \$}$ \\
$15.8 \pm 2.7^{\#, \$}$ \\
$5.2 \pm 0.6^{\#, \$}$ \\
$2.6 \pm 0.4^{\#}$ \\
$7.8 \pm 1.3^{\#}$ \\
$198 \pm 27^{\#}$ \\
$218 \pm 22^{\#}$ \\
\hline
\end{tabular}

\begin{tabular}{c} 
ANOVA $P$ value \\
\hline 0.002 \\
0.041 \\
0.004 \\
0.002 \\
0.095 \\
$<0.001$ \\
$<0.001$ \\
0.009 \\
0.001 \\
$<0.001$ \\
$<0.001$ \\
$<0.001$ \\
0.012 \\
$<0.001$
\end{tabular}

Values are mean \pm S.E.M. ( $n=5-12$ per group). Pairwise comparisons as follow: $* P \leq 0.05 C$ vs TFD; $\# P \leq 0.05$ TFD vs Exe; $\$ P \leq 0.05 C$ vs Exe. Adipo-IR $\mathrm{R}_{\mathrm{i}}$ adipose tissue insulin resistance index; FFA, free fatty acids; HIRI, hepatic insulin resistance index. 
there are increased rates of hepatic mitochondrial TCA cycle metabolism as well as of EGP which may promote disease progression from simple steatosis to NASH. Hepatic insulin resistance index (Wang et al. 2014) calculated as EGP $\times$ fasting plasma insulin was not significantly lower in exenatide-treated animals with NASH (Table 1). Utilizing NMR-based isotopomer analysis of plasma glucose, we investigated whether exenatide therapy could alleviate dysfunctional mitochondrial metabolism induced by a TFD diet. Consistent with previous findings (Patterson et al. 2016, Kalavalapalli et al. 2018), both mitochondrial TCA cycle activity and EGP were elevated in mice with NASH following a 24-week TFD diet (Fig. 1). An overall increase in mitochondrial TCA cycle metabolism in NASH mice was also evident from the concurrent increase in the rates of mitochondrial anaplerosis and pyruvate cycling, both pathways instrumental in fueling TCA cycle metabolism. EGP (Fig. 1A), mitochondrial TCA cycle activity (Fig. 1B), anaplerosis (Fig. 1C) and pyruvate cycling (Fig. 1D) were non-significantly reduced after exenatide treatment compared to TFD-fed animals. Of note, reductions in these parameters were strongly correlated between them (TCA flux and anaplerosis: $r=0.86, P<0.0002$ ).
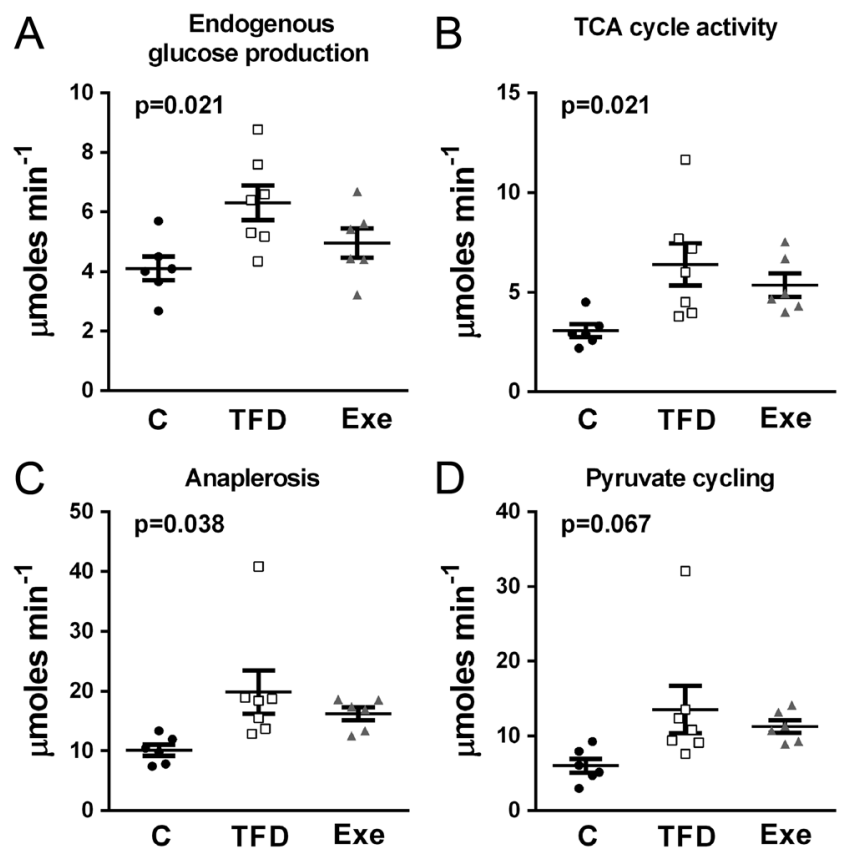

Figure 1

Endogenous glucose production and hepatic mitochondrial TCA cycle activity in mice with NASH treated with exenatide. (A) Endogenous glucose production, (B) TCA cycle flux, (C) anaplerosis and (D) pyruvate cycling were determined using ${ }^{13} \mathrm{C}$-NMR-based isotopomer analysis. Values in scatter dot plot are represented as mean \pm S.E. $(n=5-7$ per group). $P$ value is overall F statistics (ANOVA). C, Control mice; TFD, high trans-fat high-fructose fed mice; Exe, mice fed TFD diet treated with exenatide.

\section{Exenatide treatment decreases hepatic triglyceride content and improves hepatocyte lipidomic profile of mice with NASH}

In the setting of obesity, insulin-resistant adipose tissue promotes hepatic steatosis and hepatocyte injury from lipotoxicity (Cusi 2012, Lomonaco et al. 2012, Bril et al. 2017, Sunny et al. 2017). As exenatide treatment significantly reduced triglycerides in liver of mice with NASH (Table 1), we determined the levels of various classes of hepatocyte lipids, for example TGs, DAGs, Cer, LPC, PC, PE and PG using highresolution LC-MS/MS. There was a trend observed in the reduction of total intrahepatic lipid content (Fig. 2A) and total TGs (Fig. 2C). Most importantly, exenatide significantly decreased accumulation of DAGs (Fig. 2E) and Cer (Fig. 2G) in comparison to mice with NASH.

We also conducted a PLS-DA analysis to illustrate the changes in total and multiple classes of lipids. These score plots of individual metabolite classes exhibited a clear separation and allowed us to understand which variables are responsible for the separation between all three groups of mice (C, TFD and Exe). All the PLS-DA models were validated and considered high relevant if the quality of prediction $\left(Q^{2}\right)$ was greater than 0.5 and the reproducibility of the model $\left(R^{2}\right)$ was greater than 0.6 . The PLS-DA analysis of total lipids (Fig. 2B), total TGs (Fig. 2D), total DAGs (Fig. 2F) and total Cer (Fig. 2H) showed a clear separation between the groups treated with exenatide versus TFD, which was particularly striking for DAGs.

Targeted metabolic analysis demonstrated a significant reduction of several specific DAGs (Fig. 3B) and some TGs (Fig. 3A) and Cer (Fig. 3C) species following exenatide treatment. There were no significant changes observed in some of the lipid intermediates from other classes including lysophosphatidylcholines, phosphatidylcholines, phosphatidylethanolamines and phosphatidylglycerols with exenatide administration (Supplementary Fig. 1, see section on supplementary data given at the end of this article). Fold change in different sub species of LPC, PC, PE and PG are presented in Supplementary Fig. 2. Taken together, the improvements in the lipidomic profile following exenatide treatment reflect the global decrease in hepatic lipid byproducts, most clearly of DAGs, reflecting improved mitochondrial lipid oxidation.

\section{Exenatide reverses the activation of genes that lead to steatosis and inflammation in mice with NASH}

To better understand the mechanism of action of exenatide to reduce intracellular lipid accumulation, 
B
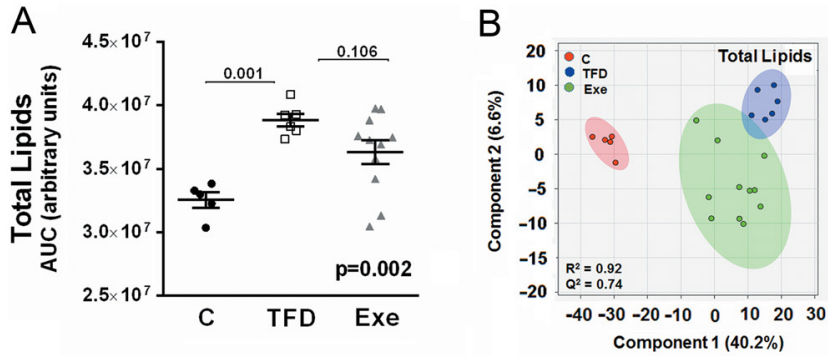

C
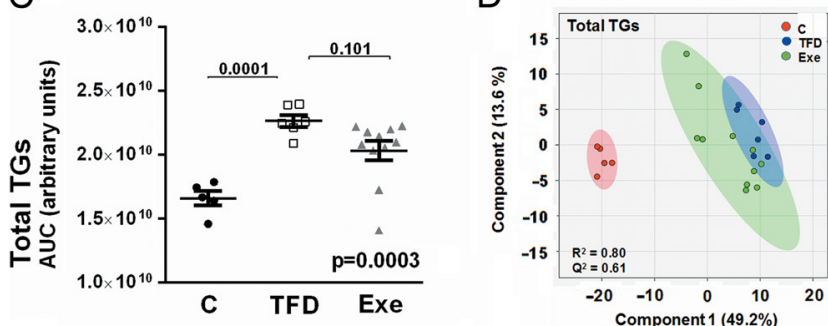

E

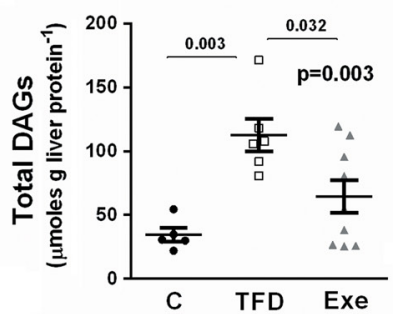

F

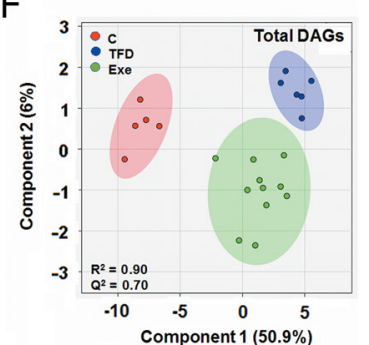

G

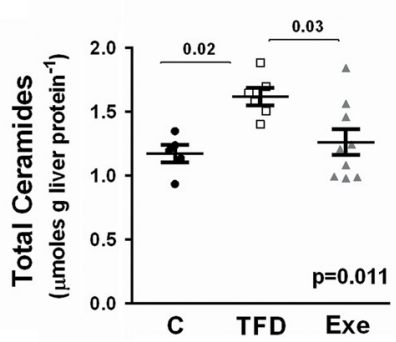

$\mathrm{H}$

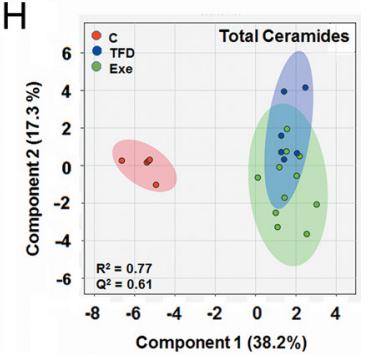

Figure 2

Exenatide administration decreases multiple lipid classes in the liver of mice with NASH. The hepatic content of each lipid class and their respective PLS-DA score plots for the three groups of mice (C $(n=5)$, TFD $(n=6)$ and Exe $(n=11))$ are presented for (A and B) total lipids, (C and D) total triglycerides, ( $E$ and $F$ ) total diacylglycerols and ( $G$ and $H$ ) total ceramides. $P$ value is overall F statistics (ANOVA) and post hoc analyses adjusted for multiple comparisons. C, control mice; Exe, mice fed TFD diet supplemented with Exenatide; TFD, high trans-fat high-fructose fed mice. A full colour version of this figure is available at https://doi.org/10.1530/JOE-19-0007.

we measured hepatic mRNA levels of genes related to carbohydrate, lipid and mitochondrial metabolism among the three groups (Fig. 4 and Table 2). Exenatide regulated the expression of genes involved in mitochondrial fatty acid oxidation and mitochondrial biogenesis (Fig. 4A, B and $\mathrm{C}$ ). Exenatide treatment resulted in the upregulation of peroxisome proliferator activated receptor alpha (Ppara) (Fig. 4A). This was associated with a significant

reduction in liver triglyceride content $(P=0.02)$ and an increase in liver protein content $(P=0.003)$, as shown in Table 1. Concurrently, we observed in mice treated with exenatide a significant reduction in hepatocyte cluster of differentiation 36 (Cd36) (Fig. 4D) and a nonsignificant reduction in Srebp1c (Fig. 4E) gene expression, genes involved in fatty acid transport and lipogenesis, respectively. There was also an amelioration by exenatide administration in the expression of genes linked to inflammation and fibrosis, as indicated by significantly lower mRNA levels of tumor necrosis factor a (Tnfa), tissue inhibitor of metalloproteinase 1 (Timp1) and matrix metallopeptidase 13 (Mmp13) (Fig. 4G, H and I) as well as a significant reduction in plasma cytokine levels of IL $\beta$ and TNF $\alpha$ (Table 1). Exenatide treatment was associated with a non-significant reduction in lobular inflammation (3.0 \pm 0.0 vs $2.6 \pm 0.2, P=0.18)$ and fibrosis stages $(1.8 \pm 0.2$ vs $1.4 \pm 0.2, P=0.24)$ compared to TFD-fed animals. Taken together, these results suggest that exenatide treatment reduces TFD-induced defects like hepatic steatosis, inflammation and fibrosis.

\section{Exenatide treatment reverses defects in adipose tissue gene expression in mice with NASH linked to insulin resistance}

Exenatide treatment improved adipose tissue insulin sensitivity and overall function as evidenced by a $~ 30 \%$ reduction in plasma FFA levels and also as indicated by adipose tissue insulin resistance index $\left(\right.$ Adipo- $\mathrm{IR}_{\mathrm{i}}$ ), calculated as fasting FFA $\times$ insulin $(P=0.001)$ (Table 1$)$. To confirm this, we examined mRNA levels of key genes involved in mitochondrial fatty acid metabolism and inflammation in adipose tissue of control. As observed in Fig. 5, exenatide administration downregulated gene expression of forkhead box O1 (Foxo1), uncoupling protein 2 (Ucp2), $C d 36$ and a non-significant reduction of long-chain acyl-CoA dehydrogenase (Lcad), alpha smooth muscle actin (aSma) and Toll-like receptor 4 (Tlr4) genes. Taken together, these results indicate that exenatide therapy improved overall adipose tissue function in mice with NASH.

\section{Discussion}

The mechanism(s) of action by which GLP-1RAs may reverse steatohepatitis remain incompletely understood. Animal models (Satapati et al. 2015, Patterson et al. 2016, Kalavalapalli et al. 2018) and human studies (Sunny 

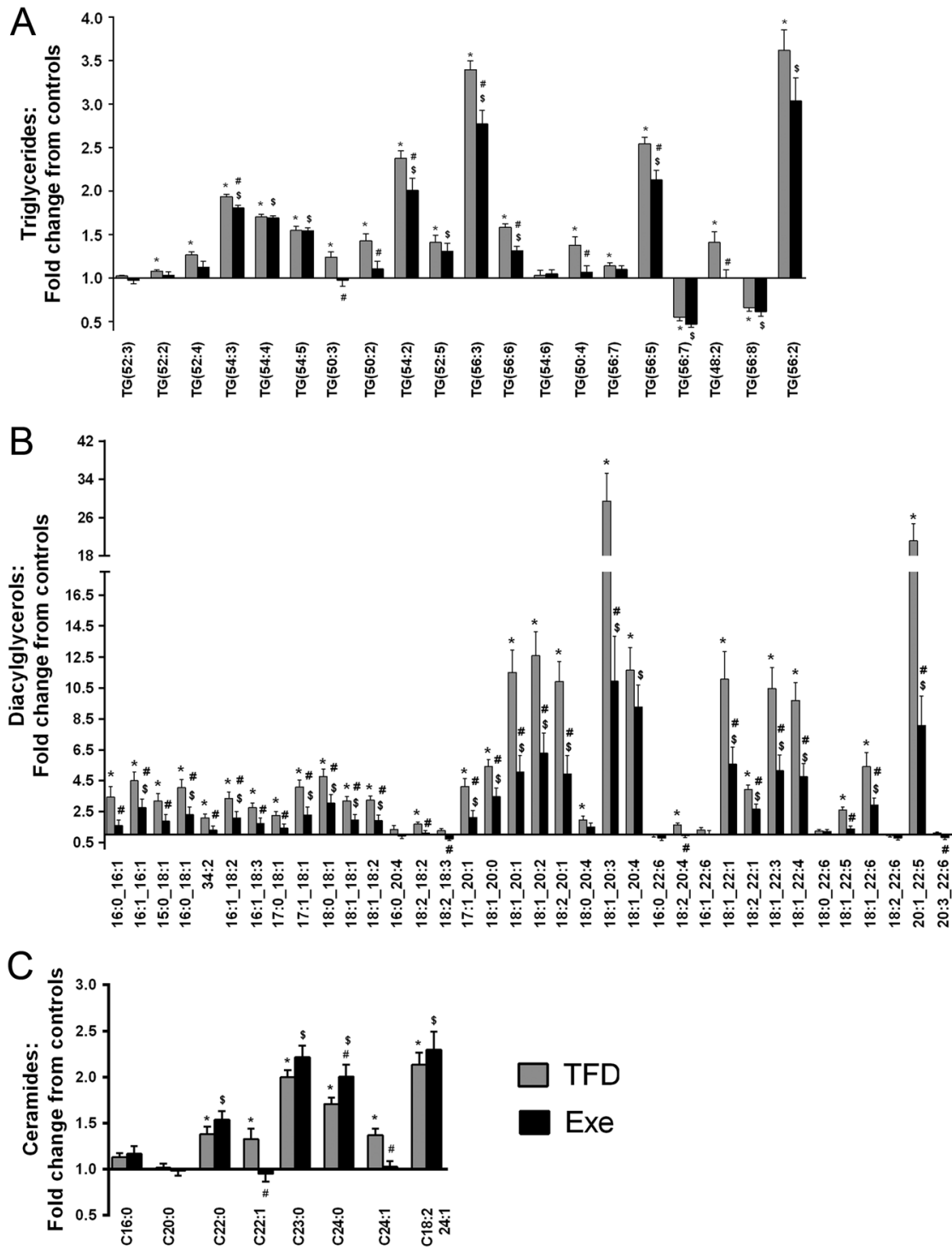

\begin{abstract}
Figure 3
High-resolution LC-MS/MS-based lipidomic profiling of hepatic (A) triglycerides, (B) diacylglycerols and (C) ceramides demonstrate significant changes in several of these lipid intermediates in response to exenatide administration in mice with NASH. Values for each bars are expressed as mean fold change from the control mice average \pm S.E. ( $n=5$-11 per group). Comparisons between the two groups were performed using unpaired Student's t-test. ${ }^{*} P \leq 0.05$ between $C$ and TFD, $\# P \leq 0.05$ between TFD and Exe, $\$ P \leq 0.05$ between $C$ and Exe. $C$, control mice; Exe, mice fed TFD diet supplemented with exenatide; TFD, high trans-fat high-fructose fed mice.
\end{abstract}

et al. 2011, 2017) suggest that lipotoxicity may trigger inflammation, cell death and activate fibrogenic pathways in NASH by inducing mitochondrial dysfunction. Because some GLP-1RAs have proven to be beneficial in NASH (Van Can et al. 2014, Abdul-Ghani et al. 2017, Dhir \& Cusi 2018), we felt compelled to examine more carefully their role to modulate mitochondrial function in this setting and their effect on the accumulation of toxic lipid metabolites that trigger lipotoxicity. We found that in a validated diet-induced mouse model of NASH (Patterson et al. 2016), exenatide administration induced weight loss, improved adipose tissue insulin sensitivity as indicated by Adipo- $\mathrm{IR}_{\mathrm{i}}$, slightly alleviated hepatic mitochondrial oxidative TCA flux and resulted in a reduction of lipotoxic intermediates, in particular DAGs. Taken together, these results expand on the role of GLP-1RAs on liver

(c) 2019 Society for Endocrinology Published by Bioscientifica Ltd.
Printed in Great Britain metabolism in NAFLD and further support their clinical relevance for the management of patients with NASH.

It is well established that in NASH, dysfunctional adipose tissue promotes hepatic steatosis and drives hepatocyte lipotoxicity. Lipotoxicity occurs in parallel with elevated mitochondrial oxidative fluxes promoting high rates of ROS production and inflammation (Satapati et al. 2015, Sunny et al. 2017, Apostolopoulou et al. 2018). The higher rates of triglyceride accretion, inflammation and fibrosis during NASH is accompanied with chronically elevated mitochondrial oxidative flux through TCA cycle which further has the potential to uncouple hepatic TCA cycle activity from mitochondrial respiration by disrupting the mitochondrial electrochemical gradient and to impair ATP synthesis (Koliaki et al. 2015, Satapati et al. 2015, Apostolopoulou et al. 2018). Several animal models have 
A

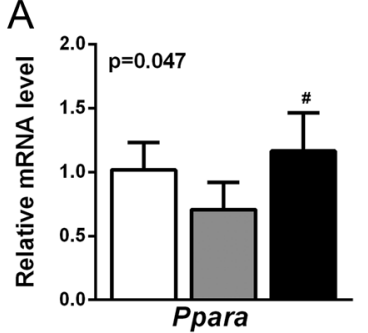

D

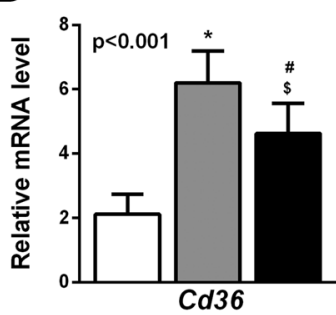

G

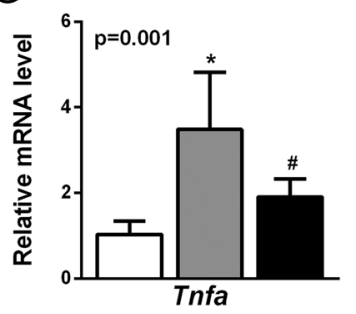

B

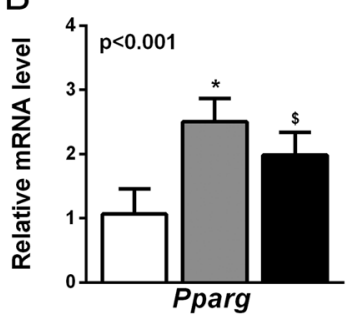

$\mathrm{E}$

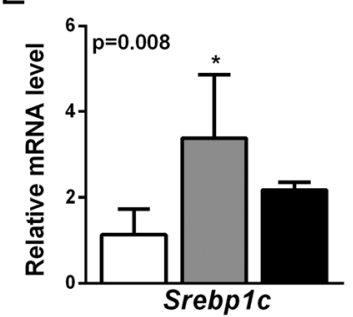

$\mathrm{H}$

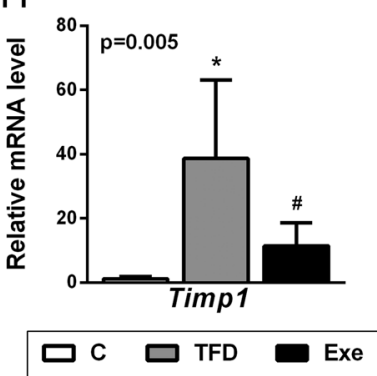

C

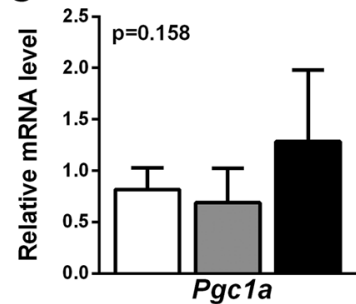

F

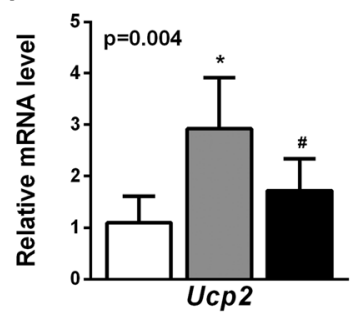

I

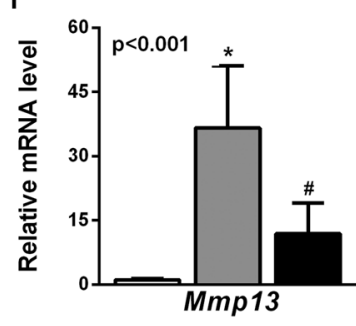

Figure 4

Trans-fat diet (TFD)-induced hepatic steatosis, inflammation and fibrosis are attenuated by exenatide treatment in mice with NASH. Changes in hepatic mRNA levels of genes related to fatty acid and lipid metabolism, inflammation and fibrogenesis in mice with NASH treated with exenatide indicates increased fat oxidation and reduced lipogenesis. (A) Ppara, (B) Pparg, (C) Pgc1a, (D) Cd36, (E) Srebp1c, (F) Ucp2, (G) Tnfa, (H) Timp1 and (I) Mmp13. Data are represented as the mean \pm s.E. $(n=5-8)$. $P$ value is overall $\mathrm{F}$ statistics (ANOVA) and post hoc analyses adjusted for multiple comparisons. ${ }^{*} P \leq 0.05$ between $C$ and TFD, $\# P \leq 0.05$ between TFD and Exe, $\$ P \leq 0.05$ between $C$ and Exe. C, control mice; Exe, mice treated with exenatide; TFD, high trans-fat high-fructose fed mice. reported positive metabolic effects of GLP-1RAs to improve hepatic insulin sensitivity and decrease steatosis, even fibrosis (Trevaskis et al. 2012), in animal models of dietinduced obesity (Lee et al. 2012, Xu et al. 2014, Seo et al. 2016). Several different mechanisms of action have been described for GLP-1 agonists, including improved insulin secretion, delayed gastric emptying, decreased appetite by central mechanisms, nausea/vomiting, among others. It is likely that a combination of the above explains the overall metabolic effects observed with these compounds, as evidenced by prior studies ( $\mathrm{Gu}$ et al. 2011, Drucker 2018). It has also been proposed that there may be hepatic GLP-1 receptors that may account for, at least part of, their beneficial action in the liver (Gupta et al. 2010, SvegliatiBaroni et al. 2011). However, other investigators have been unable to reproduce these findings (Panjwani et al. 2013, Pyke et al. 2014, Jin \& Weng 2016). A lowering of plasma AST/ALT and of hepatic steatosis with GLP-1RAs has been reported in several (Armstrong et al. 2013, Eguchi et al. 2015, Vanderheiden et al. 2016, Petit et al. 2017), but not all (Tang et al. 2015, Smits et al. 2016), studies. Early proofof-concept studies reported that GLP-RAs could improve hepatic steatosis in obesity and/or diabetes (Jendle et al. 2009, Cuthbertson et al. 2012, Ohki et al. 2012).
However, this effect appears more linked to weight loss than a specific effect on the liver. For instance, a recent review examining the effect of liraglutide in NAFLD, weight loss occurred in eight out of nine studies (Cusi 2019). In the only controlled study without weight loss, there was no change in liver steatosis on imaging (Smits et al. 2016). The hepatic effects appear related to indirect mechanisms linked to weight loss or changes in plasma insulin and glucagon levels, or improvement of insulin resistance (either induced by weight loss or unclear pathways). However, acute short-term studies giving exenatide that improve hepatic insulin sensitivity. For instance, exenatide infusion lowers hepatic glucose production in humans in whom insulin and glucagon secretion have been kept constant by means of a somatostatin infusion (Prigeon et al. 2003, Seghieri et al. 2013). Exenatide may also acutely ameliorate hepatic insulin resistance during an OGTT independent of changes of glucagon concentration (Gastaldelli et al. 2016). Therefore, we are unable to say whether the changes reported in steatosis, insulin action or TCA cycle activity by exenatide in this study may include mechanisms beyond weight loss.

In an elegant study, Armstrong et al. (2016a) reported that 48 weeks of treatment with liraglutide of patients with 
Table 2 Expression of genes related to carbohydrate, lipid and mitochondrial metabolism in liver of overnight-fasted TFD and exenatide administered mice compared to control mice.

\begin{tabular}{lc}
\hline Gene & C \\
\cline { 1 - 1 } Cpt1a & $1.0 \pm 0.06$ \\
Lcad & $1.0 \pm 0.10$ \\
Hmgcs2 & $1.0 \pm 0.14$ \\
Fgf21 & $1.0 \pm 0.45$ \\
Pepck & $1.0 \pm 0.17$ \\
Foxo1 & $1.0 \pm 0.44$ \\
Glut1 & $1.0 \pm 0.13$ \\
Cycs & $1.0 \pm 0.07$ \\
Chrebp & $1.0 \pm 0.31$ \\
Acc1 & $1.0 \pm 0.30$ \\
Acc2 & $1.0 \pm 0.09$ \\
Fasn & $1.0 \pm 0.16$ \\
II6 & $1.0 \pm 0.25$ \\
TIr4 & $1.0 \pm 0.64$ \\
PC III & $1.0 \pm 0.30$ \\
aSma & $1.0 \pm 0.16$ \\
Sirt1 & $1.0 \pm 0.09$ \\
Bckdk & $1.0 \pm 0.11$ \\
Bckdha & $1.0 \pm 0.16$ \\
Bcat2 & $1.0 \pm 0.09$ \\
\hline
\end{tabular}

\begin{tabular}{cc}
\hline TFD \\
\hline $0.60 \pm 0.06^{*}$ \\
$0.82 \pm 0.02$ \\
$0.63 \pm 0.09 *$ \\
$1.64 \pm 0.54$ \\
$1.18 \pm 0.23$ \\
$0.77 \pm 0.22$ \\
$1.52 \pm 0.26$ \\
$0.94 \pm 0.18$ \\
$0.71 \pm 0.16$ \\
$1.11 \pm 0.15$ \\
$0.94 \pm 0.16$ \\
$1.15 \pm 0.23$ \\
$0.79 \pm 0.14$ \\
$0.73 \pm 0.16$ \\
$12.40 \pm 3.37 *$ \\
$0.97 \pm 0.15$ \\
$1.15 \pm 0.08$ \\
$0.94 \pm 0.04$ \\
$0.69 \pm 0.08$ \\
$0.81 \pm 0.13$
\end{tabular}

\begin{tabular}{ll}
\hline \multicolumn{1}{c}{ Exe } \\
\hline $0.80 \pm 0.05^{\$}$ \\
$0.95 \pm 0.07$ \\
$0.64 \pm 0.05^{\$}$ \\
$0.54 \pm 0.09$ \\
$1.85 \pm 0.25^{\#, \$}$ \\
$1.07 \pm 0.36$ \\
$1.35 \pm 0.19$ \\
$1.03 \pm 0.10$ \\
$0.87 \pm 0.11$ \\
$0.87 \pm 0.14$ \\
$0.71 \pm 0.11 \$$ \\
$1.07 \pm 0.09$ \\
$0.79 \pm 0.14$ \\
$0.67 \pm 0.19$ \\
$5.69 \pm 1.65^{\$}$ \\
$0.96 \pm 0.18$ \\
$1.15 \pm 0.11$ \\
$1.06 \pm 0.07$ \\
$1.10 \pm 0.13^{\#}$ \\
$1.01 \pm 0.09$
\end{tabular}

Values are means \pm S.E. $(n=5-6)$

$\star P \leq 0.1 \mathrm{C}$ and TFD, $\# P \leq 0.1 \mathrm{TFD}$ and Exe and $\$ P \leq 0.1 \mathrm{C}$ and Exe.

biopsy-proven NASH led to a significant improvement in liver histology, and an improvement in insulin sensitivity at the level of the liver and adipose tissue at least in a subset of patients (Armstrong et al. 2016b). GLP-1RAs reduce hepatic lipogenesis, may increase hepatic glucose uptake/glycogen synthesis and improve VLDL clearance (Ben-Shlomo et al. 2011, Armstrong et al. 2016b, Seo et al. 2016). Dutour et al. (2016) reported a reduction in liver and epicardial fat accumulation in patients with T2DM. More recently, using a novel dynamic PET technique, Gastaldelli et al. (2016) reported that exenatide may improve both hepatic and adipose tissue insulin resistance.

In prior work, we have provided evidence that a TFD diet fed for 24 weeks induces hyperglycemia, hyperinsulinemia, along with hepatic steatosis, inflammation and fibrosis in a validated animal model of NASH (Patterson et al. 2016, Kalavalapalli et al. 2018). It has also been reported that GLP-1RAs may increase fatty acid oxidation in rodents (Ding et al. 2006, Gupta et al. 2010, Ben-Shlomo et al. 2011, Armstrong et al. 2016b). To better understand the role of GLP-1RAs in NASH, we applied a unique stable isotope, state-of-the-art technique, to gain insights on how exenatide may work to reduce plasma glucose, FFA and plasma/hepatic triglycerides. We established for the first time that, at least in part, exenatide reverses steatosis and hepatocyte lipotoxicity from the accumulation of toxic byproducts of incomplete fatty acid metabolism (Fig. 3).
The hepatic content of some of the lipid classes was reduced, in particular DAGs, as shown in their respective separation by PLS-DA score plots (Fig. 2). Accumulation of DAGs has been clearly linked with impairment of insulin signaling and hepatic insulin resistance (Birkenfeld \& Shulman 2014, Szendroedi et al. 2014). The reduction of DAGs by exenatide and improvement in hepatic insulin action are consistent with the above and offer a better understanding to the mechanism of action of GLP1-RAs in NAFLD. The trivially decreased TCA flux, in tandem with a reduction in DAGs, appears to link improved mitochondrial function with less accumulation of toxic lipid metabolites. Of note, there was also a reduction in some, but not all, ceramide subspecies (Fig. 3C). Ceramides have been recently implicated as being associated with activation of inflammatory pathways in patients with NASH (Apostolopoulou et al. 2018). This may occur by ameliorating excessive rates of TCA activity, anaplerosis and pyruvate cycling, which decreased by 15-20\%, although changes did not reach statistical significance. Future studies will more clearly establish the relative contribution of DAGs and ceramides, as well as TCA activity, to the natural history of necroinflammation and fibrosis in NASH.

Elevated mitochondrial TCA cycle activity has the potential to further drive pathways of ROS production and inflammation. Compared to mice with NASH, the lower EGP and hepatic TCA cycle activity induced by 
A

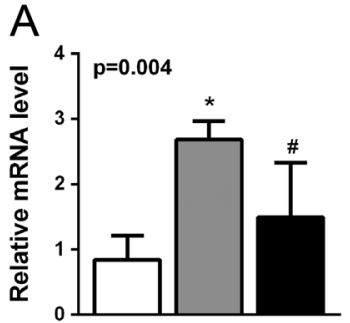

Fox01

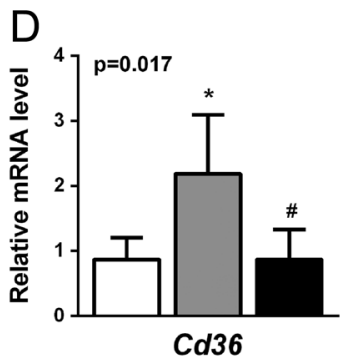

$B$
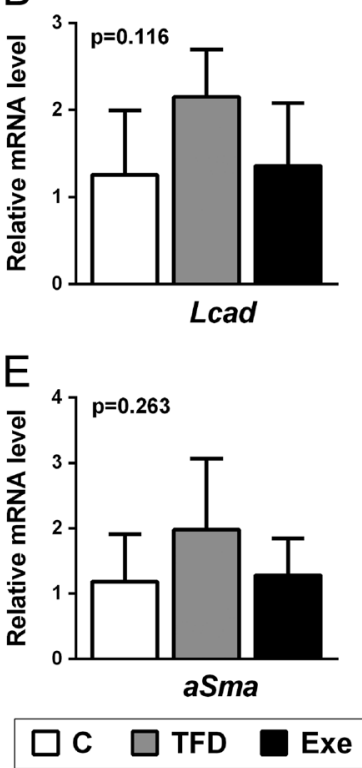

C
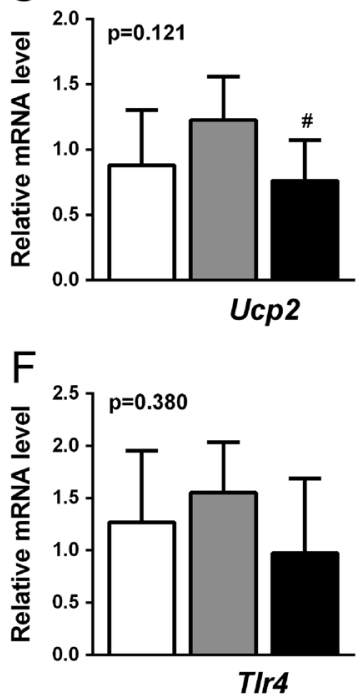

\section{Figure 5}

Abnormal adipose tissue gene expression profile is normalized by exenatide treatment in mice with $\mathrm{NASH}$. Treatment with exenatide improves the expression in adipose tissue of genes involved in mitochondrial fatty acid metabolism (A) Foxo1, (B) Lcad, (C) Ucp2, (D) Cd36, (E) aSma, (F) T/r4. Data are represented as the mean \pm S.E. $(n=5-8)$. $P$ value is overall $F$ statistics (ANOVA) and post-hoc analyses adjusted for multiple comparisons. ${ }^{*} P \leq 0.05$ between $C$ and TFD, $\# P \leq 0.05$ between TFD and Exe, ${ }^{\$} P \leq 0.05$ between $C$ and Exe. $C$, control mice; Exe, mice treated with exenatide; TFD, high trans-fat high-fructose fed mice. exenatide was associated with changes in hepatic mRNA levels of genes related to fatty acid and lipid metabolism, inflammation and fibrogenesis (Fig. 4). Previous work in a high-fat-induced obesity mouse model has shown that Exendin-4 may reduce hepatic triglyceride accumulation via sirt1 signaling (Lee et al. 2012, Xu et al. 2014) or by activating $\beta$-catenin (Seo et al. 2016). Exenatide administration also significantly down regulated mRNA levels of hepatocyte lipogenic transcription factors like Srebp1c and Cd36. Finally, whether the effects of exenatide to decrease TCA flux are secondary to improved adipose tissue function with diminished FFA flux to the liver (as indicated by the decrease in plasma FFA concentration, Adipo- $\mathrm{IR}_{\mathrm{i}}$ and adipose tissue expression of genes involved in lipid metabolism and inflammation) or rather related to a direct effect on hepatocyte signaling pathways, remains to be established.

In summary, this work indicates that exenatide ameliorated TCA flux and significantly reduced hepatic triglycerides, insulin resistance and lipotoxicity. Whether these changes are exclusively secondary to weight loss, or may be at least in part the result of a direct effect on hepatocyte mitochondrial function or other mechanisms, remains to be established. In any case, the findings led additional credence that GLP-1RAs play an important role in the future management of patients with NASH.

\section{Supplementary data}

This is linked to the online version of the paper at https://doi.org/10.1530/ JOE-19-0007.

(c) 2019 Society for Endocrinology Published by Bioscientifica Ltd. Printed in Great Britain
Declaration of interest

The authors declare that there is no conflict of interest that could be perceived as prejudicing the impartiality of the research reported.

\section{Funding}

This research did not receive any specific grant from any funding agency in the public, commercial or not-for-profit sector.

\section{Author contribution statement}

S K, F B, N E S and K C conception and design of research; S K, J G, A V , and N E S performed experiments; S K, T J G, and N E S analyzed data; S K, F B, J G, T J G, N E S, and K C interpreted results of experiments; S K, and N E S prepared figures; S K, and K C drafted manuscript; S K, F B, J G, A V, T J G, $\mathrm{NES}$, and $\mathrm{K} C$ edited and revised manuscript; $S \mathrm{~K}$, and $\mathrm{K} C$ approved the final version of the manuscript.

\section{Acknowledgements}

The authors are grateful to James R Rocca and the Advanced Magnetic Resonance Imaging and Spectroscopy Facility at the University of Florida, Gainesville for assistance with carbon-13 based NMR isotopomer analysis. Jeremy Koelmel, Matthew Rabe at University of Florida provided valuable assistance with data analysis.

\section{References}

Abdul-Ghani M, Migahid O, Megahed A, Adams J, Triplitt C, Defronzo RA, Zirie M \& Jayyousi A 2017 Combination therapy with exenatide plus pioglitazone versus basal/bolus insulin in patients with poorly controlled type 2 diabetes on sulfonylurea plus metformin: the Qatar study. Diabetes Care 40 325-331. (https://doi.org/10.2337/ dc16-1738) 
Amori RE, Lau J \& Pittas AG 2007 Efficacy and safety of incretin therapy in type 2 diabetes: systematic review and meta-analysis. JAMA 298 194-206. (https://doi.org/10.1001/jama.298.2.194)

Apostolopoulou M, Gordillo R, Koliaki C, Gancheva S, Jelenik T, De Filippo E, Herder C, Markgraf D, Jankowiak F, Esposito I, et al. 2018 Specific hepatic sphingolipids relate to insulin resistance, oxidative stress, and inflammation in nonalcoholic steatohepatitis. Diabetes Care 41 1235-1243. (https://doi.org/10.2337/dc17-1318)

Armstrong MJ, Gaunt P, Aithal GP, Barton D, Hull D, Parker R, Hazlehurst JM, Guo K, Team LT, Abouda G, Abouda G, et al. 2016 a Liraglutide safety and efficacy in patients with non-alcoholic steatohepatitis (LEAN): a multicentre, double-blind, randomised, placebo-controlled phase 2 study. Lancet 387 679-690. (https://doi. org/10.1016/S0140-6736(15)00803-X)

Armstrong MJ, Houlihan DD, Rowe IA, Clausen WH, Elbrond B, Gough SC, Tomlinson JW \& Newsome PN 2013 Safety and efficacy of liraglutide in patients with type 2 diabetes and elevated liver enzymes: individual patient data meta-analysis of the lead program. Alimentary Pharmacology and Therapeutics 37 234-242. (https://doi. org/10.1111/apt.12149)

Armstrong MJ, Hull D, Guo K, Barton D, Hazlehurst JM, Gathercole LL, Nasiri M, Yu J, Gough SC, Newsome PN, et al. 2016b Glucagon-like peptide 1 decreases lipotoxicity in non-alcoholic steatohepatitis. Journal of Hepatology 64 399-408. (https://doi.org/10.1016/j. jhep.2015.08.038)

Ben-Shlomo S, Zvibel I, Shnell M, Shlomai A, Chepurko E, Halpern Z, Barzilai N, Oren R \& Fishman S 2011 Glucagon-like peptide-1 reduces hepatic lipogenesis via activation of AMP-activated protein kinase. Journal of Hepatology 54 1214-1223. (https://doi.org/10.1016/j. jhep.2010.09.032)

Birkenfeld AL \& Shulman GI 2014 Nonalcoholic fatty liver disease, hepatic insulin resistance, and type 2 diabetes. Hepatology $\mathbf{5 9}$ 713-723. (https://doi.org/10.1002/hep.26672)

Blonde L \& Russell-Jones D 2009 The safety and efficacy of liraglutide with or without oral antidiabetic drug therapy in type 2 diabetes: an overview of the lead 1-5 studies. Diabetes, Obesity and Metabolism 11 (Supplement 3) 26-34. (https://doi.org/10.1111/j.14631326.2009.01075.x)

Bril F \& Cusi K 2016 Nonalcoholic fatty liver disease: the new complication of type 2 diabetes mellitus. Endocrinology and Metabolism Clinics of North America 45 765-781. (https://doi.org/10.1016/j. ecl.2016.06.005)

Bril F, Barb D, Portillo-Sanchez P, Biernacki D, Lomonaco R, Suman A, Weber MH, Budd JT, Lupi ME \& Cusi K 2017 Metabolic and histological implications of intrahepatic triglyceride content in nonalcoholic fatty liver disease. Hepatology 65 1132-1144. (https:// doi.org/10.1002/hep.28985)

Charlton MR, Burns JM, Pedersen RA, Watt KD, Heimbach JK \& Dierkhising RA 2011 Frequency and outcomes of liver transplantation for nonalcoholic steatohepatitis in the United States. Gastroenterology 141 1249-1253. (https://doi.org/10.1053/j. gastro.2011.06.061)

Clapper JR, Hendricks MD, Gu G, Wittmer C, Dolman CS, Herich J, Athanacio J, Villescaz C, Ghosh SS, Heilig JS, et al. 2013 Diet-induced mouse model of fatty liver disease and nonalcoholic steatohepatitis reflecting clinical disease progression and methods of assessment. American Journal of Physiology: Gastrointestinal and Liver Physiology 305 G483-G495. (https://doi.org/10.1152/ajpgi.00079.2013)

Cusi K 2012 Role of obesity and lipotoxicity in the development of nonalcoholic steatohepatitis: pathophysiology and clinical implications. Gastroenterology 142 711-725.e6. (https://doi. org/10.1053/j.gastro.2012.02.003)

Cusi K 2016 Treatment of patients with type 2 diabetes and nonalcoholic fatty liver disease: current approaches and future directions. Diabetologia 59 1112-1120. (https://doi.org/10.1007/ s00125-016-3952-1)
Cusi K 2019 Incretin-based therapies for the management of NAFLD in patients with type 2 diabetes. Hepatology [epub]. (https://doi. org/10.1002/hep.30670)

Cuthbertson DJ, Irwin A, Gardner CJ, Daousi C, Purewal T, Furlong N, Goenka N, Thomas EL, Adams VL, Pushpakom SP, et al. 2012 Improved glycaemia correlates with liver fat reduction in obese, type 2 diabetes, patients given glucagon-like peptide-1 (GLP-1) receptor agonists. PLoS ONE 7 e50117. (https://doi.org/10.1371/journal. pone.0050117)

Dhir G \& Cusi K 2018 Glucagon like peptide-1 receptor agonists for the management of obesity and non-alcoholic fatty liver disease: a nove therapeutic option. Journal of Investigative Medicine 66 7-10. (https:// doi.org/10.1136/jim-2017-000554)

Ding X, Saxena NK, Lin S, Gupta NA \& Anania FA 2006 Exendin-4, a glucagon-like protein-1 (GLP-1) receptor agonist, reverses hepatic steatosis in ob/ob mice. Hepatology 43 173-181. (https://doi. org/10.1002/hep.21006)

Dong Y, Lv Q, Li S, Wu Y, Li L, Li J, Zhang F, Sun X \& Tong N 2017 Efficacy and safety of glucagon-like peptide-1 receptor agonists in non-alcoholic fatty liver disease: a systematic review and metaanalysis. Clinics and Research in Hepatology and Gastroenterology $\mathbf{4 1}$ 284-295. (https://doi.org/10.1016/j.clinre.2016.11.009)

Drucker DJ 2018 Mechanisms of action and therapeutic application of glucagon-like peptide-1. Cell Metabolism 27 740-756. (https://doi. org/10.1016/j.cmet.2018.03.001)

Dutour A, Abdesselam I, Ancel P, Kober F, Mrad G, Darmon P, Ronsin O, Pradel V, Lesavre N, Martin JC, et al. 2016 Exenatide decreases liver fat content and epicardial adipose tissue in patients with obesity and type 2 diabetes: a prospective randomized clinical trial using magnetic resonance imaging and spectroscopy. Diabetes, Obesity and Metabolism 18 882-891. (https://doi.org/10.1111/ dom.12680)

Eguchi Y, Kitajima Y, Hyogo H, Takahashi H, Kojima M, Ono M, Araki N, Tanaka K, Yamaguchi M, Matsuda Y, et al. 2015 Pilot study of liraglutide effects in non-alcoholic steatohepatitis and non-alcoholic fatty liver disease with glucose intolerance in Japanese patients (LEAN-J). Hepatology Research 45 269-278. (https://doi.org/10.1111/ hepr.12351)

Folch J, Lees M \& Sloane Stanley GH 1957 A simple method for the isolation and purification of total lipides from animal tissues. Journal of Biological Chemistry 226 497-509.

Gastaldelli A, Gaggini M, Daniele G, Ciociaro D, Cersosimo E, Tripathy D, Triplitt C, Fox P, Musi N, Defronzo R, et al. 2016 Exenatide improves both hepatic and adipose tissue insulin resistance: a dynamic positron emission tomography study. Hepatology 64 2028-2037. (https://doi. org/10.1002/hep.28827)

Gu W, Lloyd DJ, Chinookswong N, Komorowski R, Sivits G Jr, Graham M, Winters KA, Yan H, Boros LG, Lindberg RA, et al. 2011 Pharmacological targeting of glucagon and glucagon-like peptide 1 receptors has different effects on energy state and glucose homeostasis in diet-induced obese mice. Journal of Pharmacology and Experimental Therapeutics 338 70-81. (https://doi.org/10.1124/ jpet.111.179986)

Gupta NA, Mells J, Dunham RM, Grakoui A, Handy J, Saxena NK \& Anania FA 2010 Glucagon-like peptide-1 receptor is present on human hepatocytes and has a direct role in decreasing hepatic steatosis in vitro by modulating elements of the insulin signaling pathway. Hepatology 51 1584-1592. (https://doi.org/10.1002/ hep.23569)

Jendle J, Nauck MA, Matthews DR, Frid A, Hermansen K, During M, Zdravkovic M, Strauss BJ, Garber AJ \& Lead 2009 Weight loss with liraglutide, a once-daily human glucagon-like peptide-1 analogue for type 2 diabetes treatment as monotherapy or added to metformin, is primarily as a result of a reduction in fat tissue. Diabetes, Obesity and Metabolism 11 1163-1172. (https://doi.org/10.1111/j.14631326.2009.01158.x) https://joe.bioscientifica.com

https://doi.org/10.1530/JOE-19-0007 (c) 2019 Society for Endocrinology Published by Bioscientifica Ltd. Printed in Great Britain 
Jin T \& Weng J 2016 Hepatic functions of GLP-1 and its based drugs: current disputes and perspectives. American Journal of Physiology: Endocrinology and Metabolism 311 E620-E627. (https://doi org/10.1152/ajpendo.00069.2016)

Kalavalapalli S, Bril F, Koelmel JP, Abdo K, Guingab J, Andrews P, Li WY, Jose D, Yost RA, Frye RF, et al. 2018 Pioglitazone improves hepatic mitochondrial function in a mouse model of nonalcoholic steatohepatitis. American Journal of Physiology: Endocrinology and Metabolism 315 E163-E173. (https://doi.org/10.1152/ ajpendo.00023.2018)

Koelmel JP, Kroeger NM, Gill EL, Ulmer CZ, Bowden JA, Patterson RE, Yost RA \& Garrett TJ 2017 Expanding lipidome coverage using LC-MS/MS data-dependent acquisition with automated exclusion list generation. Journal of the American Society for Mass Spectrometry 28 908-917. (https://doi.org/10.1007/s13361-017-1608-0)

Koliaki C, Szendroedi J, Kaul K, Jelenik T, Nowotny P, Jankowiak F, Herder C, Carstensen M, Krausch M, Knoefel WT, et al. 2015 Adaptation of hepatic mitochondrial function in humans with non-alcoholic fatty liver is lost in steatohepatitis. Cell Metabolism 21 739-746. (https://doi.org/10.1016/j.cmet.2015.04.004)

Lee J, Hong SW, Chae SW, Kim DH, Choi JH, Bae JC, Park SE, Rhee EJ, Park CY, Oh KW, et al. 2012 Exendin-4 improves steatohepatitis by increasing Sirt1 expression in high-fat diet-induced obese C57BL/6J mice. PLoS ONE 7 e31394. (https://doi.org/10.1371/journal. pone.0031394)

Lomonaco R, Ortiz-Lopez C, Orsak B, Webb A, Hardies J, Darland C, Finch J, Gastaldelli A, Harrison S, Tio F, et al. 2012 Effect of adipose tissue insulin resistance on metabolic parameters and liver histology in obese patients with nonalcoholic fatty liver disease. Hepatology $\mathbf{5 5}$ 1389-1397. (https://doi.org/10.1002/hep.25539)

Mack CM, Moore CX, Jodka CM, Bhavsar S, Wilson JK, Hoyt JA, Roan JL, Vu C, Laugero KD, Parkes DG, et al. 2006 Antiobesity action of peripheral exenatide (exendin-4) in rodents: effects on food intake, body weight, metabolic status and side-effect measures. International Journal of Obesity 30 1332-1340. (https://doi.org/10.1038/ sj.ijo.0803284)

Ohki T, Isogawa A, Iwamoto M, Ohsugi M, Yoshida $\mathrm{H}$, Toda N, Tagawa $\mathrm{K}$, Omata M \& Koike K 2012 The effectiveness of liraglutide in nonalcoholic fatty liver disease patients with type 2 diabetes mellitus compared to sitagliptin and pioglitazone. Scientific World Journal 2012 496453. (https://doi.org/10.1100/2012/496453)

Panjwani N, Mulvihill EE, Longuet C, Yusta B, Campbell JE, Brown TJ, Streutker C, Holland D, Cao X, Baggio LL, et al. 2013 GLP-1 receptor activation indirectly reduces hepatic lipid accumulation but does not attenuate development of atherosclerosis in diabetic male ApoE(-/-) mice. Endocrinology 154 127-139. (https://doi.org/10.1210/en.2012-1937)

Patterson RE, Kalavalapalli S, Williams CM, Nautiyal M, Mathew JT, Martinez J, Reinhard MK, Mcdougall DJ, Rocca JR, Yost RA, et al. 2016 Lipotoxicity in steatohepatitis occurs despite an increase in tricarboxylic acid cycle activity. American Journal of Physiology: Endocrinology and Metabolism 310 E484-E494. (https://doi. org/10.1152/ajpendo.00492.2015)

Petit JM, Cercueil JP, Loffroy R, Denimal D, Bouillet B, Fourmont C, Chevallier O, Duvillard L \& Verges B 2017 Effect of liraglutide therapy on liver fat content in patients with inadequately controlled Type 2 diabetes: the lira-NAFLD study. Journal of Clinical Endocrinology and Metabolism 102 407-415. (https://doi.org/10.1210/jc.2016-2775)

Pluskal T, Castillo S, Villar-Briones A \& Oresic M 2010 MZmine 2: modular framework for processing, visualizing, and analyzing mass spectrometry-based molecular profile data. BMC Bioinformatics 11 395. (https://doi.org/10.1186/1471-2105-11-395)

Prigeon RL, Quddusi S, Paty B \& D'alessio DA 2003 Suppression of glucose production by GLP-1 independent of islet hormones: a novel extrapancreatic effect. American Journal of Physiology: Endocrinology and Metabolism 285 E701-E707. (https://doi.org/10.1152/ ajpendo.00024.2003)
Pyke C, Heller RS, Kirk RK, Orskov C, Reedtz-Runge S, Kaastrup P, Hvelplund A, Bardram L, Calatayud D \& Knudsen LB 2014 GLP-1 receptor localization in monkey and human tissue: novel distribution revealed with extensively validated monoclonal antibody. Endocrinology 155 1280-1290. (https://doi.org/10.1210/en.2013-1934)

Rinella ME 2015 Nonalcoholic fatty liver disease: a systematic review. JAMA 313 2263-2273. (https://doi.org/10.1001/jama.2015.5370)

Satapati S, Sunny NE, Kucejova B, Fu X, He TT, Mendez-Lucas A, Shelton JM, Perales JC, Browning JD \& Burgess SC 2012 Elevated TCA cycle function in the pathology of diet-induced hepatic insulin resistance and fatty liver. Journal of Lipid Research 53 1080-1092. (https://doi.org/10.1194/jlr.M023382)

Satapati S, Kucejova B, Duarte JA, Fletcher JA, Reynolds L, Sunny NE, He T, Nair LA, Livingston KA, Fu X, et al. 2015 Mitochondrial metabolism mediates oxidative stress and inflammation in fatty liver. Journal of Clinical Investigation 125 4447-4462. (https://doi. org/10.1172/JCI82204)

Seghieri M, Rebelos E, Gastaldelli A, Astiarraga BD, Casolaro A, Barsotti E, Pocai A, Nauck M, Muscelli E \& Ferrannini E 2013 Direct effect of GLP-1 infusion on endogenous glucose production in humans. Diabetologia 56 156-161. (https://doi.org/10.1007/s00125012-2738-3)

Seo MH, Lee J, Hong SW, Rhee EJ, Park SE, Park CY, Oh KW, Park SW \& Lee WY 2016 Exendin-4 inhibits hepatic lipogenesis by increasing beta-catenin signaling. PLOS ONE 11 e0166913. (https://doi. org/10.1371/journal.pone.0166913)

Smits MM, Tonneijck L, Muskiet MH, Kramer MH, Pouwels PJ, PietersVan Den Bos IC, Hoekstra T, Diamant M, Van Raalte DH \& Cahen DL 2016 Twelve week liraglutide or sitagliptin does not affect hepatic fat in type 2 diabetes: a randomised placebo-controlled trial. Diabetologia 59 2588-2593. (https://doi.org/10.1007/s00125-016-4100-7)

Sunny NE, Satapati S, Fu X, He T, Mehdibeigi R, Spring-Robinson C, Duarte J, Potthoff MJ, Browning JD \& Burgess SC 2010 Progressive adaptation of hepatic ketogenesis in mice fed a high-fat diet. American Journal of Physiology: Endocrinology and Metabolism 298 E1226-E1235. (https://doi.org/10.1152/ajpendo.00033.2010)

Sunny NE, Parks EJ, Browning JD \& Burgess SC 2011 Excessive hepatic mitochondrial TCA cycle and gluconeogenesis in humans with nonalcoholic fatty liver disease. Cell Metabolism 14 804-810. (https:// doi.org/10.1016/j.cmet.2011.11.004)

Sunny NE, Bril F \& Cusi K 2017 Mitochondrial adaptation in nonalcoholic fatty liver disease: novel mechanisms and treatment strategies. Trends in Endocrinology and Metabolism 28 250-260. (https:// doi.org/10.1016/j.tem.2016.11.006)

Svegliati-Baroni G, Saccomanno S, Rychlicki C, Agostinelli L, De Minicis S, Candelaresi C, Faraci G, Pacetti D, Vivarelli M, Nicolini D, et al. 2011 Glucagon-like peptide-1 receptor activation stimulates hepatic lipid oxidation and restores hepatic signalling alteration induced by a high-fat diet in nonalcoholic steatohepatitis. Liver International 31 1285-1297. (https://doi.org/10.1111/j.14783231.2011.02462.x)

Szendroedi J, Yoshimura T, Phielix E, Koliaki C, Marcucci M, Zhang D, Jelenik T, Muller J, Herder C, Nowotny P, et al. 2014 Role of diacylglycerol activation of PKCtheta in lipid-induced muscle insulin resistance in humans. PNAS 111 9597-9602. (https://doi.org/10.1073/ pnas.1409229111)

Tang A, Rabasa-Lhoret R, Castel H, Wartelle-Bladou C, Gilbert G, Massicotte-Tisluck K, Chartrand G, Olivie D, Julien AS, De Guise J, et al. 2015 Effects of insulin glargine and liraglutide therapy on liver fat as measured by magnetic resonance in patients with type 2 diabetes: a randomized trial. Diabetes Care 38 1339-1346. (https://doi. org/10.2337/dc14-2548)

Trevaskis JL, Griffin PS, Wittmer C, Neuschwander-Tetri BA, Brunt EM, Dolman CS, Erickson MR, Napora J, Parkes DG \& Roth JD 2012 Glucagon-like peptide-1 receptor agonism improves metabolic, biochemical, and histopathological indices of nonalcoholic 
steatohepatitis in mice. American Journal of Physiology: Gastrointestinal and Liver Physiology 302 G762-G772. (https://doi.org/10.1152/ ajpgi.00476.2011)

Van Can J, Sloth B, Jensen CB, Flint A, Blaak EE \& Saris WH 2014 Effects of the once-daily GLP-1 analog liraglutide on gastric emptying, glycemic parameters, appetite and energy metabolism in obese, nondiabetic adults. International Journal of Obesity 38 784-793. (https:// doi.org/10.1038/ijo.2013.162)

Vanderheiden A, Harrison LB, Warshauer JT, Adams-Huet B, Li X, Yuan Q, Hulsey K, Dimitrov I, Yokoo T, Jaster AW, et al. 2016 Mechanisms of action of liraglutide in patients with type 2 diabetes treated with high-dose insulin. Journal of Clinical Endocrinology and Metabolism 101 1798-1806. (https://doi.org/10.1210/jc.2015-3906)

Wang Y, Parlevliet ET, Geerling JJ, Van Der Tuin SJ, Zhang H, Bieghs V, Jawad AH, Shiri-Sverdlov R, Bot I, De Jager SC, et al. 2014 Exendin-4 decreases liver inflammation and atherosclerosis development simultaneously by reducing macrophage infiltration. British Journal of Pharmacology 171 723-734. (https://doi.org/10.1111/bph.12490)

Xu F, Li Z, Zheng X, Liu H, Liang H, Xu H, Chen Z, Zeng K \& Weng J 2014 SIRT1 mediates the effect of GLP-1 receptor agonist exenatide on ameliorating hepatic steatosis. Diabetes 63 3637-3646. (https:// doi.org/10.2337/db14-0263)

Received in final form 17 April 2019

Accepted 23 April 2019 (c) 2019 Society for Endocrinology Published by Bioscientifica Ltd.
Printed in Great Britain 